\title{
EL Thelos de la Protección de los DATOS Personales ANTe EL Derecho Al ACCESO A LA INFORMACIÓN
}

THE "THELOS" OF PERSONAL DATA PROTECTION IN CONFRONT OF THE RIGHT TO ACCESS TO THE INFORMATION

Javier Nájera Montiel *

Resume: Este texto tiene por objeto el análisis y estudio de tres figuras de gran relieve, como es el derecho a la información, los datos personales y la intimidad, instituciones que actualmente han adquirido un valor trascendental, traduciéndose en nuevas formas de poder y manipulación, instrumentos y medios de control. Por tal motivo, en este texto se analizará en primer término, el derecho al acceso a la información. En segundo término, los datos personales. Finalizará esta investigación con el estudio de la intimidad, como el aspecto axiológico de la protección de los datos personales.

Palabras clave: Datos personales, datos sensibles, acceso a la información, teleología jurídica, derecho de la información

Abstract: This text aims to analyze and study of three high-profile figures, such as the right to information, personal data and privacy, institutions currently have acquired a transcendental value, resulting in new forms of power and handling, tools and control means. Therefore, we first analyzed the right of access to information and personal data then. This investigation will finalize with the study of privacy, as the axiological aspect of the protection of personal data.

* Licenciado y Maestro en Derecho por la Universidad Nacional Autónoma de México. Diplomado en Derecho Penal por la Universidad de Estudios de Postgrado en Derecho. Máster en Informática y Derecho por la Universidad Complutense de Madrid. javier@najeramontiel.com.mx 
Keywords: Personal data, sensitive information, information access, communication law

Fecha de recepción: 28-02-2007

Fecha de aceptación: 15-05-2007

"Ningún hombre es una isla, algo completo en sí mismo, todo hombre es un fragmento del continente, una parte de un conjunto"

John Donne

\section{Consideraciones generaleS}

En los reinantes días, paradigma bautizado como la sociedad de la información ${ }^{1}$, los datos e información representan y mutan en elementos de valor significativo y de trascendencia relevante para la actividad humana, en atención directa a la asunción del conocimiento como instrumento de poder, control y manipulación ${ }^{2}$.

1 Esta evocación se realiza tomando en consideración presupuestos conceptuales parciales, cuya principal característica es su aplicación restringida, a nivel fáctico. Es decir, al afirmarse la existencia de la sociedad "de la información" se niega el carácter humano de la misma al apelar solo a un ser humano ideal, negándole su real y actual posición, contexto y destino, asumiendo únicamente la idea del deber ser. De hecho, esta denominación reniega al unísono de una gran porción de seres humanos que por factores económicos, políticos, sociales, culturales o biológicos no tienen acceso a medios de comunicación e información, como son la televisión, el radio, el teléfono o Internet y, por ende, se encuentran vedados o restringidos al acceso y conocimiento de toda clase de datos e información, dando paso a la presencia de una visión propia de carácter distorsionada, limitada, restringida o impuesta de la propia realidad.

${ }^{2}$ El almacenamiento, tratamiento, modificación y transmisión de datos, información, imágenes y sonidos es ya un uso generalizado que se traduce en un gran factor de poder y control por sí mismo. En este orden de ideas, se ha convertido la recolección, proceso y distribución de información y datos, en una actividad esencial en todos los ámbitos que constituyen esta sociedad, ya que la información y los datos representan valiosos y preciados objetos del comercio.

Ius Humani, v. 1 (2008/9), p. 178 
$\mathrm{Al}$ reconocerse normativamente el valor y posición actual de los datos y la información, surge y se posiciona el derecho a la información. La información y el reconocimiento normativo a su acceso, se encuentran circunscritos por la misma presencia de otros derechos, valores e intereses, como es la seguridad nacional, ciertos intereses sociales ${ }^{3}, \mathrm{y}$ los derechos de terceros ${ }^{4}$.

Uno de los linderos al ejercicio del derecho a la información es la intimidad, cuya materialización se plasma a través de los datos personales. En el presente texto, grosso modo, se expondrá el derecho a la información en cuanto a su concepción misma; en segundo lugar se da paso a una definición de dato personal, al análisis del aspecto axiológico de la protección de los datos personales frente al derecho al acceso a la información, para finalizar con una aproximación, de carácter general, a la intimidad del ser humano.

\section{EL DERECHO A LA INFORMACIÓN}

El ser humano que se erige actualmente, se enfrenta ante una serie de nuevos paradigmas, además de la reconfiguración de los ya existentes, gestación y cambio alimentado y potenciado por una diversidad de factores, como son:

a) La presencia, uso y destino de las tecnologías de la información, $v . g$. Internet, telefonía celular o la comunicación satelital, entre otras formas de telecomunicación.

b) La presencia, uso y destino de la biotecnología, e. $g$. inseminación artificial, la nanotecnología, el análisis o alteración genética y celular.

c) La globalización del capital financiero y económico.

\footnotetext{
${ }^{3}$ V. gr. el orden público, la salud, la moral publica, la protección de grupos vulnerables.

${ }^{4}$ Exempli gratia, la dignidad, la intimidad, el honor, la imagen, el secreto profesional o epistolar, el secreto financiero o comercial, la honra o la estimación.
} 
d) La reconfiguración de las nociones de tiempo y espacio, y la eliminación de barreras de carácter temporal y espacial.

e) La creación de nuevas barreras de tipo funcional y económica.

f) Una sobrevaloración de la información y datos.

El actual periodo, que ha sido denominado como la sociedad de la información, es un paradigma que se caracteriza por la creación o mutación de una serie de problemáticas de toda índole que se sustentan o potencian en la información, la comunicación, la globalización, la ciencia o la tecnología, y provocan el surgimiento de un nuevo hombre, en cuanto a la comprensión de sí mismo como tal.

Hoy por hoy se observa el nacimiento, creación y desarrollo de una serie de problemáticas que tienen sus efectos en el Derecho, es decir, conflictos posicionados en un nivel normativo, fáctico o axiológico que giran en torno a varias figuras e instituciones básicas, como es la información y el acceso a la misma, además de la intimidad del ser humano.

En el actual contexto, social al reconocerse normativamente el valor y la posición actual de los datos e información, surge el derecho a la información como reflejo directo de la libertad y, en específico, de la libertad de expresión y del respeto a la verdad, en estrecha relación con el deseo aparente de evitar la existencia de datos e información manipuladas, incompletas o falsas que permitan el sustento de la construcción de una realidad artificial.

El derecho a la información se constituye de:

a) El derecho a informar.

a. La libertad de expresión.

b. La libertad de imprenta.

b) El derecho a estar informado.

a. Recibir información completa, objetiva y oportuna. 
c) El derecho a atraerse información.

a. Acceso a la información (cfr. López Ayllón, 2000, p. 163).

El derecho a la información es una institución jurídica reconocida en una gran diversidad de sistemas jurídicos, a través de sus normas fundamentales, por ejemplo, en el sistema jurídico mexicano, el derecho a la información se reconoce en el artículo sexto de la constitución federal, precepto legal que a la letra dice lo siguiente:

Art. $6^{\circ}$. La manifestación de las ideas no será objeto de ninguna inquisición judicial o administrativa, sino en el caso de que ataque a la moral, los derechos de tercero, provoque algún delito o perturbe el orden público; el derecho a la información será garantizado por el Estado.

En este sentido, en la Constitución política de Ecuador se reconoce normativamente el derecho a la información, a través de su artículo 81, el cual establece lo siguiente:

Art. 81. El Estado garantizará el derecho a acceder a fuentes de información; a buscar, recibir, conocer y difundir información objetiva, veraz, plural, oportuna y sin censura previa, de los acontecimientos de interés general, que preserve los valores de la comunidad, especialmente por parte de periodistas y comunicadores sociales.

Por lo que respecta al derecho al acceso a la información, esta figura normativa se traduce en una acción de intervención orientada a la búsqueda de la verdad, a través de la recopilación de datos y de información en poder de la autoridad, y que se traduce en un reflejo directo del ser humano que ejerce un grado de autonomía sobre un determinado espacio de libertad, con la finalidad de descubrir, crear o moldear una verdad, mediante la información.

Como una libertad positiva, el derecho a la información tiene por objeto: 
a) Ejercer plenamente la facultad y necesidad natural de todo hombre de conocerse a sí mismo, a su entorno y su contexto, a través del conocimiento de determinada información y datos.

b) Con la información y datos obtenidos, construir, crear, moldear o deformar una realidad como una verdad generalmente aceptada o asumida.

Partiendo de lo anterior, el papel que viene desempeñando el derecho al acceso a la información, se traduce en los efectos que a continuación se señalan:

a) Dragar prácticas corruptivas, discrecionales e ilegales de la administración pública.

b) Posibilitar la elaboración de juicios de valor sobre los actos de autoridad.

c) Permitir el ejercicio del carácter ciudadano de la persona.

d) Permitir la rendición de cuentas de la autoridad (cfr. Ackerman M., \& Sandoval, 2005, p. 20).

En principio, el acceso a la información es un derecho que recae y norma la actividad de la autoridad. Sin embargo, para conquistar y alcanzar una sociedad plenamente abierta y transparente, este derecho deberá aplicarse también al sector privado, es decir, a aquellas personas físicas o naturales, empresas, entidades o corporaciones del sector privado, que realicen o ejecuten funciones esenciales, a nivel estatal con efectos o consecuencias para el interés social ${ }^{5}$. Un reflejo directo

\footnotetext{
${ }^{5}$ Existen empresas con actividades cuyos efectos se ven reflejados en el medio ambiente o en la biodiversidad de una zona o continente determinados, como son las empresas generadoras de energía, o extractoras de petróleo y gas; o corporaciones cuyas investigaciones recaen en factores que implican al ser humano, en cuanto a su estructura genética o biológica, como son las empresa farmacéuticas, o las empresas dedicadas a la biotecnología. Ambos ejemplos tratan de empresas privadas, cuyos actos, procedimientos o actividades tienen una repercusión a nivel social, que afecta de
} Ius Humani, v. 1 (2008/9), p. 182 
de esta exigencia se ve plasmado en el artículo primero de la ley orgánica de acceso a la información pública de Ecuador, precepto legal que establece lo siguiente:

Art. 1. Objeto. Es garantizar solo a los ciudadanos ecuatorianos el acceso a la información pública en manos de la entidad pública o privada.

Por el contrario, existen sistemas jurídicos en donde aún se regula el derecho al acceso a la información solo en manos del sector público; como muestra ejemplar se encuentra la ley federal de transparencia y acceso a la información pública gubernamental de México que establece en su artículo primero, lo siguiente:

Art. 1. La presente Ley es de orden público. Tiene como finalidad proveer lo necesario para garantizar el acceso de toda persona a la información en posesión de los Poderes de la Unión, los órganos constitucionales autónomos o con autonomía legal, y cualquier otra entidad federal.

De hecho, para lograr constituir una sociedad abierta y plenamente transparente, en donde el hombre como persona, juegue un papel fundamental como punto de partida y destino, es necesario que el acceso a la información se extienda a los denominados poderes invisibles o de facto, en búsqueda de un control y sujeción de los mismos, bajo reglas y lineamientos previamente fijados o concertados.

El derecho al acceso a la información representa un instrumento que viabiliza el poder adquirir datos e información para ejercer un juicio de valoración crítico y analítico sobre los mismos con la posibilidad de validarlas, convalidarlas, corregirlas, negarlas, modificarlas o hacerlas propias, con la finalidad de crear

manera directa al ser humano y produce un interese social respecto de los efectos de sus propias actividades empresariales ante el propio hombre, su sociedad y el mismo Estado. 
o construir una verdad sobre la cual se sustente una realidad deseada o anhelada.

Como toda institución jurídica, el derecho al acceso a la información no se caracteriza por ser absoluto e ilimitado, en cuanto a su reconocimiento y aplicación, sino que este derecho se encuentra circunscrito por la presencia de una serie de derechos, bienes, valores e intereses que el hombre en sociedad fija para su preservación, búsqueda o construcción.

Entre las fronteras del derecho al acceso a la información reconocidas legalmente se encuentra un primer grupo, integrado por:
a) La seguridad nacional ${ }^{6}$.
b) El orden público.
c) La salud general.
d) La moral publica 7 .
e) La protección de grupos vulnerables ${ }^{8}$.

\footnotetext{
${ }^{6} \mathrm{El}$ artículo tercero de la ley federal de transparencia y acceso a la información pública gubernamental del Estado mexicano, define en su fracción XII a la seguridad nacional, en los siguientes términos: "XII. Seguridad nacional: Acciones destinadas a proteger la integridad, estabilidad y permanencia del Estado mexicano, la gobernabilidad democrática, la defensa exterior y la seguridad interior de la federación, orientadas al bienestar general de la sociedad que permitan el cumplimiento de los fines del Estado constitucional".

${ }^{7}$ La moral pública o social es una expectativa o exigencia ético-social que deriva de un juicio de carácter moral, sobre la conducta que permite la interacción humana. Esta expectativa no se caracteriza por ser reiterativa, ya que "...no basta que una conducta se vea masivamente repetida para que podamos considerarla como expresión de la moral positiva de una sociedad..." (Ollero, 2007, p. 82).

8 Actualmente existen seres humanos identificados y clasificados entre sí como miembros integrantes de los denominados grupos vulnerables. Individuos que asumen como motivo de su desigualdad, la sola existencia de determinada característica física, biológica o social. Esta característica o faceta que por sí misma se traduce en un grado o nivel de ventaja o desventaja, de carácter económica, política o social. Entre los grupos vulnerables que hoy en día se reconocen socialmente, se encuentran los siguientes: a) Los niños. b) Las mujeres que son madres solteras. c) Las personas longevas o de la tercera edad.
}

Ius Humani, v. 1 (2008/9), p. 184 
Estos límites del derecho al acceso a la información se caracterizan por exhibir un criterio basado en un interés colectivo, el cual es mayor al beneficio particular, representado por el derecho de acceso a la información de un sujeto, evitándose con ello un perjuicio social.

Otra característica relevante es el criterio establecido para solucionar o resolver los conflictos que se presentan cuando existen dos o más normas jurídicas aplicables a una misma situación de facto, criterio basado en el grado del interés colectivo. Este criterio se traduce en la aplicación de una norma sobre otra al caso en concreto con base en el interés colectivo, el cual es mayor al beneficio particular.

Existen situaciones de facto que representan puntos de conflicto al ser reguladas por dos o más normas jurídicas, en las que cada una de ellas cuenta, representan o son guiadas por diversos valores reconocidos y anhelados. Es en este momento cuando existe un conflicto de carácter normativo, en cuanto a la aplicación de una norma que se diferencia de otra norma aplicable al mismo caso en concreto por la presencia y búsqueda de valores jurídicos diversos.

Sin embargo, el criterio correcto a seguir ante la presencia de conflictos de normas, como es el derecho al acceso a la información y la protección de los datos personales, es el cimentado en la ponderación del derecho, con base en su importancia (cfr. Alexy, 2006, p. 2). La limitación de un derecho no debe basarse solo en la existencia de un perjuicio social, sino que se debe buscar el derecho que logre o cumpla con el fin que persigue el propio Estado, en la forma en que afecte menos al individuo.

El derecho al acceso a la información también se encuentra limitado por otros derechos, intereses o valores, como son:

a) La dignidad.

b) La intimidad, a través de la protección de los datos personales. 
c) El honor.

d) La imagen.

e) El secreto profesional o epistolar.

f) El secreto comercial.

g) El secreto fiscal o financiero.

h) La honra.

i) La estimación.

Este grupo de derechos se caracteriza por la búsqueda y protección de un interés particular, plenamente identificado y tangible, cuyo beneficio gira en torno a un individuo o a una persona moral, como es el caso del secreto comercial, impositivo o fiscal.

Es importante recalcar que las excepciones al derecho al acceso a la información deberán ser establecidas y delimitadas de forma clara, y precisando los criterios a seguir, linderos entre los cuales se encuentra la intimidad $\mathrm{y}$, por ende, su objetivación a través de los datos e información de carácter personal.

\section{LOS DATOS PERSONALES}

El hombre es un ente racional, cuyo destino adjudicado es la autodeterminación de sí mismo. Exterioriza una esencia de carácter multidimensional con tres elementos antagónicos entre sí que comparten un origen y una finalidad común; el carácter íntimo, individual y social de todo ser humano.

Derivado en gran medida del carácter multidimensional del hombre surge la imperiosa necesidad de un orden y control general que será ejecutado e instrumentado a través de una serie de mecanismos de poder y control. De las entrañas mismas de esta necesidad emerge el Derecho, como mecanismo formal de control individual que refleja y responde a las necesidades de una colectividad, en busca del mantenimiento, establecimiento, creación o defensa de los intereses dominantes de una comunidad. 
A lo largo de la historia ha existido una figura que se pone a la vista como fundamento, justificación, medio o fin del Derecho mismo, y que se traduce en la dignidad humana ${ }^{9}$. Esta figura formal y su concepción ha variado en el tiempo, en cuanto a sus elementos conceptuales o esenciales, su origen, su finalidad o su contenido, obedeciendo a la idea que se tiene de la misma como un todo o únicamente aludiendo a alguna de sus aristas o manifestaciones.

En el actual contexto social ${ }^{10}$ existen proyecciones y manifestaciones de la dignidad humana como es la libertad y, en particular, el derecho a la información, comprendido por el derecho a informar, a ser informa-do y a allegarse de información.

Entre la serie de fronteras que limitan al derecho tener acceso a la información, como especie del derecho a ésta, se encuentran los derechos de terceros, lugar en donde se ubica la intimidad, la cual se materializa mediante los datos y la información que normativamente se han denominado datos personales.

Se conceptúa al dato personal como la unidad mínima del conocimiento, de naturaleza indeterminada, referente al hombre $y$ su dignidad humana, que representa externamente los pensamientos, creencias, emociones y sensaciones que conforman el ámbito íntimo de las personas.

El dato personal es una unidad mínima del conocimiento que, en sí mismo, no es un objeto físico, un bien inmueble o mueble que represente un valor intrínseco. De hecho, el valor

\footnotetext{
${ }^{9}$ La dignidad humana es un valor supremo que se traduce en el dominio pleno ejercido por y para el hombre sobre su propia vida, facultándolo para ejercer el poder, el control y el dominio sobre sí mismo, en cuanto a sí mismo y a su propio pasado, presente y futuro.

${ }^{10} \mathrm{El}$ actual paradigma social se sustenta en cuatro elementos rectores, como son: a) Una sociedad cuyo punto de partida, contenido y fin se sustenta y gira en torno al ser humano, visto como el resultado de un proceso desenfrenado de individualidad. b) El conocimiento. c) La información. d) La cosificación de una identidad humana basada en el consumo y la comunicación.
} 
asignado al dato, y en específico al dato personal, radica en la interpretación del mismo (cfr. Nicolas Orvey, abril de 2004).

Esta unidad del saber cuenta con un significado asignado, el cual ha sido dado por:

a) Factores externos del objeto por conocer.

b) Factores internos del sujeto cognoscente.

c) Contexto del objeto por conocer y del sujeto cognoscente.

Este proceso de interpretación se traduce en la incorporación de un significado al elemento significante ${ }^{11}$, a través de juicios que conllevan elementos de valoración internos, como los sentimientos, instintos o valores; y externos, como la cultura, la religión o la política.

La indeterminación hace referencia a la falta de procesamiento de la unidad del saber, en cuanto a una persona identificada. En otras palabras, esta unidad del saber puede referirse a una persona identificada ${ }^{12}$, o identificable, como es el caso de los datos con un amplio campo de multiplicidad de sujetos reconocibles, en cuanto a su afectación ${ }^{13}$.

Para considerarse el dato como personal deberá corresponder a elementos subjetivos constituidos por proyecciones psíquicas. Es decir, para que un dato sea considerado personal deberá representar externamente los pensamientos, creencias, emociones y sensaciones que conforman

\footnotetext{
11 "El conocimiento está lejos de consistir un mero instrumento que sirva para "desentrañar" el significado inmanente de las cosas yacentes y fijas, ordenadas y dotadas con anterioridad de significado. El conocimiento stricto sensu no se limita a encontrar significados ya dispuestos, evidentes y verdaderos" (Tamayo y Salmorán, 2004, p. 136, nota al pie 10).

${ }^{12}$ La identificación de una persona física o natural, a través de su nombre y apellidos, o a través de su imagen.

${ }^{13}$ Como es el caso de los datos genéticos o la información genealógica que afecten a dos o más personas, con un origen familiar o consanguíneo común.
}

Ius Humani, v. 1 (2008/9), p. 188 
el ámbito íntimo ${ }^{14}$ de las personas, ya que el dato es la forma en que externamente se manifiesta el contenido de la dimensión íntima de las personas, ámbito que está integrado por pensamientos, creencias, emociones y sensaciones.

La ley federal de transparencia y acceso a la información pública gubernamental de México define al dato personal en su artículo tercero, fracción segunda, de la siguiente manera:

Art. 3.II. Datos personales. La información concerniente a una persona física, identificada o identificable, entre otra, la relativa a su origen étnico o racial, o que esté referida a las características físicas, morales o emocionales, a su vida afectiva y familiar, domicilio, número telefónico, patrimonio, ideología y opiniones políticas, creencias o convicciones religiosas o filosóficas, los estados de salud físicos o mentales, las preferencias sexuales, u otras análogas que afecten su intimidad; (...)

Esta concepción legal muestra un listado, de carácter ejemplificativo que exhibe una serie de inconvenientes, $e$. $g$. el uso discrecional y la ausencia de criterios empleados para determinar o delimitar los elementos conceptuales conformadores de dicha enumeración.

La presencia de este concepto legal solo se traduce en la existencia de la imperiosa necesidad de proteger y regular los datos personales, objetivo fallido al normar esta clase de datos de

\footnotetext{
${ }^{14}$ Las tres dimensiones humanas son: la social, la individual y la íntima. La dimensión social alude al desarrollo normal del ser humano, en contacto con otros seres humanos, todos asumidos y vistos entre sí como una unidad amorfa con identidad y vida propia que comparten elementos, fines y valores comunes, cuyos miembros se difuminan entre sí para convertirse en elementos sociales, traduciéndose en un yo-sociedad-nosotros. La dimensión individual se refiere al desarrollo humano como persona dentro de una unidad más restringida, es decir, entre seres humanos vistos entre sí como semejantes, con características, origen o destino común, en busca de unión, protección, reconocimiento o aprecio, y que se traduce en un yo-persona-tu. Mientras que la dimensión íntima es el ámbito en donde se posa lo propio de cada ser humano, lo esencial, lo que singulariza al ser frente a sus semejantes, aludiendo al origen de sus diversas facetas, como es su propio pasado, presente y futuro, y que se traduce en un yoindividuo-ser.
} 
forma escueta y ambigua, adolecen de claridad y precisión y gestando conflictos y contradicciones, entre los cuales se encuentra la finalidad misma de su tutela, la que normativamente gira en torno a la intimidad, aunque en realidad se traduce, en muchos casos, solo en la protección del derecho a la igualdad y a la necesidad de soledad, tranquilidad o anonimato de una persona ante la sociedad misma.

\section{ASPECTO AXIOLÓGICO DE LA TUTELA DE LOS DATOS PERSONALES}

El ser humano es un ente racional de carácter multidimensional que interactúa y se interrelaciona con lo que no es él, y con lo que es semejante a él (cfr. González Uribe, 2001, p. 184). El hombre racional se define por contar con una conciencia tanto de sí mismo como tal, como de su entorno. De hecho, en conjunción con la libertad ${ }^{15}$, autonomía y el proceso de autoconciencia, el hombre adquiere el carácter de persona.

El hombre asumido como persona es un ser que busca conocer, entender y asumir su propio entorno, contexto o realidad con un grado de sociabilidad, rasgo ontológico y esencial de la persona y una dimensión axiológica asignada, reconocida o creada sobre el mundo y su propio medio.

Como fenómeno social, producto cultural y reflejo directo del hombre mismo, el Derecho es una estructura funcional que se conforma de:

a) Hechos sociales (nivel fáctico)

b) Fines normativos (nivel axiológico)

c) Regulación normativa (nivel normativo)

\footnotetext{
${ }^{15}$ La idea de libertad gira en torno al hombre autónomo, en cuanto a sus actos, con base en una razón e interés individual de carácter idealista.
}

Ius Humani, v. 1 (2008/9), p. 190 
Por lo que respecta a los fines normativos se dice que la actividad del Derecho no solo se circunscribe a la descripción del ser de las cosas, sino que las valora, en cuanto a lo que debe ser el ser al existir una separación del ser por lo que respecta al valor mismo.

De hecho, el valor no forma parte o pertenece al ser, es decir, el valor no es el ser mismo de las cosas, ya que el valor es una proyección que el ser humano le asigna a las cosas. Por lo que un valor jurídico tiene como origen, justificación y fin al propio ser humano, como guía, cuyo cumplimiento muestra una naturaleza obligatoria al contener un carácter coercitivo (cfr. Ruíz Daza, 1967, p. 146).

En otras palabras, el Derecho como el aparato coercitivo del Estado, titular del monopolio de la violencia legítima, tiene la necesidad ontológica de orientarse con arreglo a ciertos fines, ya que todo deber significa una dirección hacía algo, siendo el valor ese algo hacia el cual es direccionado el Derecho mismo (De la Torre Martínez, 2005, p. 130).

Entre las razones esenciales de la norma jurídica en un Estado liberal ${ }^{16}$ se encuentra la preservación de la vida social, a través del reconocimiento, establecimiento o fijación de ciertos valores jurídicos que permiten guiar a la potestad individual del ciudadano frente una sociedad abierta y transparente.

El Derecho es la institución social restringida a sí misma, en cuanto a sus elementos conformadores, por no identificarse como absolutos, irrestrictos e ilimitados, sino que la aplicación de las normas jurídicas se encuentra supeditada a la presencia de otras normas con diversos valores cuya aplicación provoca un conflicto; la misma aplicación implica la ejecución de un juicio racional entre una acción realizada y un valor reconocido (cfr. Soler, 1948, p. 29).

\footnotetext{
${ }^{16}$ El Estado liberal se puede definir, en términos más generales, como el limitado o contenido por las libertades fundamentales de los ciudadanos: un Estado transparente (Rodríguez Zepeda, 2004, p. 25).
} 
El acceso a la información es un derecho humano que presupone la idea de que toda información o dato son producidos y usados por y para los individuos, cuyo valor gira en torno a la idea de verdad, a la libertad de saber, al control y la certeza. Sin embargo, este derecho no es absoluto, debiendo limitarse legalmente, de forma clara y precisa ${ }^{17}$.

Entre sus limitaciones se encuentra la protección de los datos personales, los cuales se asumen como la materialidad del ámbito íntimo del ser humano, es decir el derecho al acceso a la información se encuentra restringido por la protección de los datos personales, cuyo aspecto axiológico se localiza en la intimidad ${ }^{18}$ misma del hombre.

\section{LA INTIMIDAD}

El ser humano cuenta con una naturaleza pluridimensional, es decir, es un ente visto como un todo, conformado por tres dimensiones que obedecen a su naturaleza, esferas cuyo elemento común es su origen y finalidad, el hombre mismo, pero con expresiones y contenidos diversos.

Se dice que la existencia de las tres dimensiones distintas, cuya extensión abraza toda actividad humana, se vislumbra y

17 "El acto reglado es el que realiza la autoridad con total apego a lo que marca la ley. Mientras que el acto discrecional es el que realiza la autoridad con cierta libertad, dentro del marco de la ley. Ambos se llevan a cabo con apego a la ley, solo que en el primero la autoridad tiene que sujetarse a los pasos que estrictamente ésta le señala; en cambio, en el segundo, la misma ley le da a la autoridad una dosis de libertad para que actúe en uno u otro sentido, marcándole a su vez, ya sean mínimos o máximos" (Pérez Portilla, 2005, pp. 62-63).

${ }^{18} \mathrm{La}$ intimidad es asumida como un derecho humano plenamente reconocido a nivel constitucional en una gran diversidad de sistemas jurídicos. Por ejemplo, en la constitución política de Ecuador se reconoce este derecho en el artículo 23.8, que dice lo siguiente:

Art. 23. Sin perjuicio de los derechos establecidos en esta Constitución y en los instrumentos internacionales vigentes, el Estado reconocerá y garantizará a las personas los siguientes: (...) 8. El derecho a la honra, a la buena reputación y a la intimidad personal y familiar. La ley protegerá el nombre, la imagen y la voz de la persona.

Ius Humani, v. 1 (2008/9), p. 192 
potencia en un plano en donde el ser humano es asumido como persona, es decir cuando el Derecho lo reconoce como tal, en atención a su naturaleza y su dignidad. La persona en sociedad actúa, se desarrolla y se expresa a partir de estos tres ámbitos diferentes: el íntimo, el individual y el social, los cuales adquieren una sustantividad desde el individuo como miembro de una sociedad.

La intimidad en lo personal es entendida como aquella dimensión de reserva de carácter innato, esencial y consustancial de la naturaleza humana, cuyo objeto de protección está integrado por datos e información de naturaleza personal propias al ser humano, evitando toda intromisión, así como su difusión, velando en todo momento por la autonomía y control de los mismos, a efecto de salvaguardar la dignidad humana.

Es un bien innato originado con el inicio de la vida misma. La intimidad es considerada como una dimensión que se encuentra incorporada al ser humano por su misma naturaleza.

El elemento esencial deriva de la naturaleza misma del hombre, de contar con una proyección psíquica que se traduce en la voluntad de decisión de la forma y manera de vivir, libre de intromisiones o indiscreciones ajenas que tienden al respeto de la libertad y dignidad humanas.

Asimismo, cuenta con la cualidad de ser consustancial a la naturaleza del ser humano, ya que el hombre cuenta con tres dimensiones fundamentales: la social, la individual y la íntima. La dimensión social se refiere al desarrollo normal de una persona que se encuentra en contacto con sus semejantes, mientras que la faceta individual hace referencia al desarrollo humano de manera personal; por último, la dimensión íntima es en donde se encuentra lo propio de cada persona, lo esencial, lo que singulariza al ser.

Se habla acerca del objeto de protección de la intimidad, es decir datos e información esencial al ser humano, lo cual se traduce en la forma de materialización o exteriorización de 
pensamientos, creencias, emociones y sensaciones propias de su individualidad. Para que el manto protector de la intimidad cobije este tipo de datos e información intangible e inmaterial deberán exteriorizarse, es decir, deberán ser perceptibles para ser identificados externamente.

La intimidad protege los datos e información de carácter personal del ser humano de intromisiones que pudiesen darse; en otras palabras, los resguarda de injerencias ajenas. La intromisión puede ser de forma directa, o sea, de modo personal, o de forma indirecta, cuando se utilizan instrumentos o utensilios que permitan una interferencia a distancia.

De igual forma, la intimidad tiende a proteger los datos e información propia del ser humano de todo tipo de difusión, traduciéndose lo anterior en la protección de los mismos a la exposición del resultado obtenido de la intromisión, a través de su control.

El control de datos e información se traduce en la posibilidad de mantenerlos en reserva, además de tener la posibilidad de controlar el manejo, uso, circulación y destino de la mismos, es decir, la intimidad es conformada por dos esferas, una interna, la cual consiste en un ámbito al que no tiene o no debe tener acceso el mundo. La esfera externa es constituida por los datos e información del sujeto que trascienden a su persona.

La protección a la intimidad tiende a la salvaguarda de la dignidad humana, entendida como elemento constitutivo del ser humano, y que encuentra eco en la conciencia, lugar en donde la identidad de la persona logra su despliegue, además de una serie de acciones pasadas, presentes y futuras interrelacionadas que al ser atribuidas lógicamente a un sujeto, adquieren un sentido.

La intimidad es caracterizada por lo que a continuación se enuncia. 
1. Su existencia se condiciona a la presencia misma del hombre visto como persona ${ }^{19}$.

2. La persona es asumida como elemento esencial de carácter común ${ }^{20}$.

3. La persona emerge como miembro integrante de una colectividad $^{21}$.

4. La dignidad y su protección, como finalidad última ${ }^{22}$.

5. La sujeción a un elemento espacial de carácter subjetivo y delimitador.

6. La sujeción a un elemento temporal ${ }^{23}$ de carácter subjetivo $^{24}$ y delimitador.

7. De naturaleza innata. ${ }^{25}$

8. De naturaleza esencial, $\mathrm{y}^{26}$

9. Consustancial a la naturaleza del ser humano.

${ }^{19}$ La persona es una creación del Derecho, "ser persona es el resultado de un acto de personificación del orden jurídico" (Radbruch, 1999, p. 167).

${ }^{20}$ El hombre no es una persona en cuanto a ser viviente compuesto de cuerpo y alma, sino porque se manifiesta como un fin en sí, "ser persona significa un fin en sí" (ibídem, p. 271).

${ }^{21}$ El carácter social del ser humano se traduce en la necesidad de encontrarse en relación con otras personas.

${ }^{22}$ La dignidad se muestra, entre una diversidad de aristas, en la posesión de una especie y medida de libertad personal (cfr. Legaz y Lacambra, 1979, p. 744).

${ }^{23}$ La persona, a lo largo de su existencia, experimenta el desarrollo y ejecución de sus acciones y actos en el tiempo "como un suceso caracterizado de inmediatez; la misma es atribuible a lo que se halla en el presente" (Toboso Martín, 20 de diciembre de 2003).

${ }^{24} \mathrm{El}$ tiempo se traduce en la medida o unidad que permite la determinación y fijación de sucesos y hechos, derivando de esto la existencia de una diversidad de tiempos, $v$. $g r$. el tiempo físico, el biológico o el social. Con el tiempo al ser humano se le posibilita abarcar tanto la realidad presente como la pasada y aún la futura. La persona se muestra como un ente modificable al responder a exigencias de espacio y tiempo, mostrándose como un ser inacabado y en constante cambio, al considerarse criaturas de impulsos, humores, necesidades y deseos variables.

${ }^{25}$ Las dimensiones de la persona, v. gr. la intimidad, la vida personal y la vida social son esferas que no requieren de ninguna clase de mecanismos y requisitos artificiales o especiales para su adquisición, ya que son inherentes al ser humano.

${ }^{26}$ Sin la existencia de la intimidad, la vida personal o privada y la vida social, el ser humano visto como persona adolecería de unidad, al carecer de sustantividad para considerarse en plenitud. 
La intimidad es una dimensión que se soporta en la dignidad humana, es decir, en la visión derivada del hombre visto como un fin en sí mismo y no como un medio. Además, la relevancia actual de esta dimensión obedece estrechamente a la presencia, en primer plano, de ideas como autonomía y autoperfeccionamiento, figuras características de una visión individualista.

La intimidad es una dimensión que obedece a la necesidad natural de aislamiento o retiro en busca de soledad y paz. El aspecto íntimo emerge de la interacción de las experiencias y actividades sociales, en donde el ser humano, visto como persona $^{27}$, es objeto para sí, es decir, adopta una conducta objetiva personal hacia sí mismo, dando como resultado que la persona sea un objeto para sí (cfr. Mead H., 1973, p. 170).

Una de las razones por las cuales el hombre se permite ser un fin en sí mismo reside en la libertad misma, la cual le permite enjuiciar, valorar y controlar acciones y voluntad. En este orden de ideas y, teniendo a la libertad de entretelón, el hombre "... tiene la capacidad de reflexionar sobre sí mismo, de distanciarse de sí y convertirse en objeto de estudio" (cfr. Martí García, 2002, p. 34).

\section{ConClusión}

El instrumento de poder, control y manipulación que emerge y se posiciona en el actual paradigma social son la información y los datos, unidades del conocimiento cuya valoración no deriva de su naturaleza intrínseca, sino estriba en el juicio de valoración que se hace sobre la interpretación de los mismos.

Por tal motivo, el derecho a la información se posiciona en un plano preponderante, a través del reconocimiento del acceso a

\footnotetext{
${ }^{27}$ La persona es el ser humano en sociedad reconocido como tal por el Derecho, es decir, como un sujeto con una naturaleza racional y volitiva, caracterizado por su dignidad y libertad, dando como resultado su asimilación como un fin en sí mismo; su libertad consiste en un proceso de autodeterminación, es decir, ser responsable de los actos realizados, para que la libertad sea un medio para alcanzar un fin trascendente.
}

Ius Humani, v. 1 (2008/9), p. 196 
la información como un derecho, reflejo de la libertad, de la existencia de una necesidad y la exigencia natural a conocer y a saber.

Como contrapeso del derecho al acceso a la información existen una serie de derechos, valores e intereses, entre los que se encuentra la intimidad, la cual se asume como la dimensión humana que se materializa y expresa a través de los datos personales, los cuales, a su vez, se traducen en la unidad mínima del conocimiento que representan externamente los pensamientos, creencias, emociones y sensaciones que conforman el ámbito íntimo de las personas.

El aspecto axiológico, en cuanto a los datos personales como límite del derecho al acceso a la información, es la intimidad del ser humano, entendida como la proyección en busca de una realidad trascendental que obedece a un ser humano sumergido en un paradigma reformulado con base en sus propios elementos constitutivos. 


\section{REFERENCIAS}

Ackerman M., John \& Sandoval, I. (2005). Leyes de acceso a la información en el mundo. Cuadernos de transparencia, 07. México: IFAI.

Alexy, R. (2006). Jueces y ponderación argumentativa. México: UNAM.

De la Torre Martínez, C. (2005). La recepción de la filosofía de los valores en la filosofía del derecho. México: UNAM.

González Uribe, H. (1979). Manual de filosofía social y ciencias sociales. México: Instituto de Investigaciones Jurídicas de la UNAM.

Legaz y Lacambra, L. (1979). Filosofía del Derecho (5 edición), Madrid: Bosch.

López Ayllón, S. (2000). El derecho a la información como derecho fundamental". Derecho a la información y derechos humanos. México DF: UNAM.

Martí García, M.A. (2002). La intimidad. Navarra: EUNSA.

Mead H., G. (1973). Espíritu, persona y sociedad, traducido por Florial, Mazia. Madrid: Paídos.

Nicolas Orvey, J. (abril de 2004). Information can not be owned: there is more of a difference than many thinks. The Berkman Center for Internet and Society at Harvard Law School, 2004-05. Recuperado de http://cyber.law.harvard.edu/publications.

Ollero, A. (2007). Derechos humanos. México: UNAM.

Pérez Portilla, K. (2005). Principio de igualdad. México: UNAM.

Radbruch, G. (1999). Filosofía del derecho, (4a edición). Madrid: Comares.

Rodríguez Zepeda, J. (2004). Estado y transparencia: un paseo por la filosofía política. Cuadernos de transparencia, 4. México: IFAI.

Ruíz Daza, M. (1967). Los valores jurídicos en la metafísica del valor. México: UNAM.

Soler, S. (1948). Los valores jurídicos. La Revista Jurídica de Córdova, 1, 2.

Tamayo y Salmorán, R. (2004). Razonamiento y argumentación jurídica. México: UNAM. 
Toboso Martín, M. (20 de diciembre de 2003). Tiempo y sujeto (II). A parte rei. recuperado de http://aparterei.com.

\section{Legislación}

Constitución política de los Estados Unidos Mexicanos.

Constitución política de Ecuador.

Ley federal de transparencia y acceso a la información pública gubernamental. Publicada en el Diario Oficial de la Federación, el día 11 del mes de junio de 2002, México.

Ley orgánica de acceso a la información pública. Publicada en el Registro Oficial Nacional., número 337, el día 18 de mayo de 2004, Ecuador. 